\title{
Impact of Phenolic Substrate and Growth Temperature on the Arthrobacter chlorophenolicus Proteome
}

Maria Unell ${ }^{1}$, Paul E. Abraham ${ }^{2}$, Manesh Shah $^{3}$, Bing Zhang ${ }^{4}$, Christian Rückert ${ }^{5}$, Nathan C. VerBerkmoes $^{2}$ \& Janet K. Jansson ${ }^{1,6^{*}}$

${ }^{1}$ Department of Microbiology, Swedish University of Agricultural Sciences, Box 7025, 75007 Uppsala, Sweden.

${ }^{2}$ Chemical Sciences Division, Oak Ridge National Laboratory, Oak Ridge, TN 37831, USA.

${ }^{3}$ Life Sciences Division, Oak Ridge National Laboratory, Oak Ridge, TN 37831, USA.

${ }^{4}$ Department of Biomedical Informatics, Vanderbilt University, Nashville, TN 37232, USA. ${ }^{5}$ Institute for Genome Research and Systems Biology, Center for Biotechnology, Bielefeld University D-33594, Bielefeld, Germany.

${ }^{6}$ Lawrence Berkeley National Laboratory, Earth Sciences Division, 1 Cyclotron Road, MS 70A, Berkeley, CA, 94720 USA.

*Corresponding author:

Janet K. Jansson:

Phone (510) 486-7487

Fax (510 486-7152

e-mail: jrjansson@lbl.gov

Keywords: Arthrobacter chlorophenolicus, 4-chlorophenol, 4-nitrophenol, phenol, shotgun proteomics, 2D-LC-ES-MS/MS, hydroxyquinol dioxygenase 


\begin{abstract}
We compared the Arthrobacter chlorophenolicus proteome during growth on 4-chlorophenol, 4-nitrophenol or phenol at $5^{\circ} \mathrm{C}$ and $28^{\circ} \mathrm{C}$; both for the wild type and a mutant strain with mass spectrometry based proteomics. A label free workflow employing spectral counting identified 3749 proteins across all growth conditions, representing over $70 \%$ of the predicted genome and 739 of these proteins form the core proteome. Statistically significant differences were found in the proteomes of cells grown under different conditions including differentiation of hundreds of unknown proteins. The 4-chlorophenol-degradation pathway was confirmed, but not that for phenol.
\end{abstract}

\title{
Introduction
}

Arthrobacter chlorophenolicus is a previously described species that is capable of degrading several para-substituted phenolic compounds, such as 4-chlorophenol (4-CP), 4nitrophenol (4-NP) and 4-bromophenol (4-BP) in addition to unsubstituted phenol ${ }^{1}$, at high concentrations of $1.44,2.72$ and $12.77 \mathrm{mM}$, respectively ${ }^{2}$. These compounds are common pollutants in soil, and 4-NP, in particular, is a priority pollutant listed by the U.S.

Environmental Protection Agency

(http://www.epa.gov/waterscience/methods/pollutants.htm). A. chlorophenolicus degrades these compounds efficiently as single growth substrates and in mixtures ${ }^{3}$. This bacterium can degrade 4-CP under mesophilic $\left(28^{\circ} \mathrm{C}\right)$ and psychrophilic $\left(5^{\circ} \mathrm{C}\right)$ conditions and during repeated fluctuations between these temperature extremes ${ }^{4}$. 
A. chlorophenolicus and many other members of the actinobacteria group are common residents of soil and have high tolerance to stressful conditions encountered in the soil environment. A. chlorophenolicus cells can survive after inoculation to non-sterile soil in a presumed dormant $\operatorname{state}^{5}$, demonstrating an unusual stress tolerance that has also been reported for other Arthrobacter and related actinobacterial species ${ }^{6}$. Therefore, it would be interesting to understand the mechanisms underlying the ability of $A$. chlorophenolicus and related strains to survive and grow under these highly stressful conditions.

One adaptation mechanism to changing environmental parameters is to change the composition of fatty acids in the cell membrane. Previously, we studied adaptations of the $A$. chlorophenolicus cell membrane fatty acids to changes in concentrations of phenolic compounds and to temperature ${ }^{2}$. Clear effects on the anteiso:iso ratio of branched fatty acids were seen in response to increasing concentrations of phenols, and to an even higher extent in response to changes in growth temperature.

Our aim in this study was to examine mechanisms used by A. chlorophenolicus to adapt to growth on different phenolic compounds or temperatures at the protein level. We used a bottom-up, or "shotgun" mass spectrometry based proteomics approach" ${ }^{7,8}$ followed by label free quantitation and statistical analyses for detailed exploration of the A. chlorophenolicus proteome during growth on different phenolic compounds and at different temperatures. The shotgun proteomics approach is based on a coupling of multidimensional liquid chromatography with electrospray-tandem mass spectrometry (2D-LC-ES-MS/MS). This approach has many advantages over traditional 2-dimensional-polyacrylamide gel electrophoresis (2D PAGE-MS) ${ }^{9,10}$. With recent instrumental advances ${ }^{11,12}$ 2D-LC-MS/MS methods can identify up to half of the predicted proteins (1000-3000 protein products) in isolates in a single experiment in a few days ${ }^{13-17}$. This method is highly dependent on parallel computational analyses of the predicted proteome sequence that is cleaved and fragmented in silico and compared with MS/MS spectra via search engines such as SEQUEST $^{7}$ and 
$\operatorname{Mascot}^{18}$. The recent advent of the draft genome sequence of $A$. chlorophenolicus

(http://img.jgi.doe.gov/cgi-bin/pub/main.cgi) enabled us to specifically study its proteome using the shotgun proteomics approach.

Our specific aims in the present investigation were to determine how A. chlorophenolicus adapts its proteome in response to stress conditions, such as temperature changes between 5 and $28^{\circ} \mathrm{C}$ and to growth on different phenolic substrates. In addition, we studied a mutant strain of A. chlorophenolicus (T99), harboring a non-functional hydroxyquinol 1,2dioxygenase gene. This mutation disabled the cell's ability to grow on substituted phenols, but its growth on phenol was even better than the wild type ${ }^{19}$. Therefore, we also examined the proteome of mutant T99 and compared it to the wild type during growth on phenol to gain a better understanding of proteome adaptations to phenolic substrates.

\section{Materials and Methods}

Bacterial strains and culture conditions. Arthrobacter chlorophenolicus strain A6 was previously isolated from a soil slurry enriched with increasing concentrations of 4chlorophenol (4-CP) ${ }^{1}$. A. chlorophenolicus mutant T99 contains a chloramphenicol resistanceconferring transposon inserted into a hydroxyquinol 1,2-dioxygenase gene, disabling its ability to grow on substituted phenols ${ }^{19}$. The cells were grown in GM minimal medium ${ }^{1}$ supplemented with 4-nitrophenol (4-NP), 4-CP or phenol as previously described ${ }^{1,2}$ at $28^{\circ} \mathrm{C}$ and $5^{\circ} \mathrm{C}$. Mutant $\mathrm{T} 99$ was grown in cultures supplemented with $5 \mu \mathrm{g} \mathrm{mL} \mathrm{m}^{-1}$ chloramphenicol to select for transposon retaining cells. 4-NP and 4-CP were purchased from Sigma-Aldrich (Steinheim, Germany) and phenol from Merck (Darmstadt, Germany). The phenols were added from stock solutions to final concentrations of $100 \mu \mathrm{g} \mathrm{mL}^{-1} 4-\mathrm{NP}, 150 \mu \mathrm{g} \mathrm{mL}^{-1} 4-\mathrm{CP}$ and $400 \mu \mathrm{g} \mathrm{mL} \mathrm{L}^{-1}$ phenol. 
Cell lysis and sample preparation for 2D-LC-MS/MS. Triplicate cultures from 8 different treatments were prepared. Cells in mid-log phase of growth $\left(\mathrm{OD}_{600}=0.08-0.3\right.$, depending on growth conditions as previously determined ${ }^{1,2}$, were harvested by centrifugation at $6000 \times \mathrm{g}$ for $20 \mathrm{~min}$. They were washed once with $1.5 \mathrm{~mL}$ Tris-EDTA-buffer (TE), $\mathrm{pH}$ 7.6, at the same temperature used to grow the cells; i.e. 5 or $28^{\circ} \mathrm{C}$. Cells were pelleted by centrifugation $5 \mathrm{~min}$ at $16000 \times \mathrm{g}$ at $4^{\circ} \mathrm{C}$ and stored at $-80^{\circ} \mathrm{C}$ until further treatment.

Subsequently cell pellets were diluted in $1 \mathrm{~mL}$ TE for lysis using a FastPrep ${ }^{\circledR}-24$ cell disrupter (MP Biomedicals, Solon, $\mathrm{OH}$ ) in tubes containing $0.5 \mathrm{~mL}$ of $0.1 \mathrm{~mm}$ zirconium/silica beads (BioSpec Products, Inc., Bartlesville, OK) at a speed of $6.5 \mathrm{~m} / \mathrm{s}$ four times, $45 \mathrm{~s}$ each. The lysate was centrifuged at $7000 \times \mathrm{g}$ for $20 \mathrm{~min}$. and the supernatant was recovered. Concentrated trichloroacetic acid (TCA) was added to a volume of $10 \%$ and the samples were incubated at $4{ }^{\circ} \mathrm{C}$ overnight. The resulting precipitate was harvested by centrifugation at 16 $000 \times \mathrm{g}$ for $10 \mathrm{~min}$., and washed with ice-cold methanol. After one additional centrifugation step, the precipitate was stored at $-80^{\circ} \mathrm{C}$ until LC-MS analysis (see below). All samples were processed as follows: protein pellets were re-suspended in $6 \mathrm{M}$ guanidine $/ 10 \mathrm{mM}$ dithiothreitol (DTT) in $50 \mathrm{mM}$ Tris buffer $(\mathrm{pH} 7.6)$ and heated for $1 \mathrm{~h}$ at $60^{\circ} \mathrm{C}$. The guanidine was then diluted 6-fold with $50 \mathrm{mM}$ Tris buffer/10 $\mathrm{mM} \mathrm{CaCl}_{2}(\mathrm{pH} 7.6)$, proteins were digested into peptides with 1:100 (wt/wt) sequencing grade trypsin (Promega, Madison, WI), and cellular debris was removed by centrifugation $(3000 \times \mathrm{g}$ for $10 \mathrm{~min})$. Peptides were desalted off-line by C18 solid phase extraction (Waters, Milford, MA), concentrated (to $500 \mu \mathrm{L}$ ), filtered and aliquoted (150 $\mu \mathrm{L}$ per aliquot; entire aliquot used for each LC-MS analysis).

2D-LC-MS/MS. Two-dimensional nano LC-ES-MS/MS analysis of each biological replicate and sample type was carried out on an linear ion trap mass spectrometer (LTQ Thermo Fisher, San Jose, CA) as previously described ${ }^{13,20}$. In total eight different biological samples were analyzed with three biological replicates for each sample, except for two replicates for the samples from cultures grown on $4-\mathrm{NP}$ at $28^{\circ} \mathrm{C}$, due to insufficient protein 
quantity in the third replicate for reliable analysis. All samples were run using the same methodology on the same LC-MS system. LC columns were thoroughly washed between sample sets to avoid carry over contamination or changed out entirely. Samples were loaded onto a 2-dimensional split phase column made of strong cation exchange (SCX) and reverse phase (RP). Samples $(150 \mu \mathrm{L})$ were first loaded onto a $150 \mu \mathrm{m}$ back column packed with of 4 $\mathrm{cm}$ of RP and and $4 \mathrm{~cm}$ of SCX. This back column was then connected to a $100 \mu \mathrm{m} \mathrm{RP}$ front column with an integrated nanospray tip that was packed with $15 \mathrm{~cm}$ of RP. The column system was placed into a nanospray source (Proxeon, Denmark), directly in front of the LTQ mass spectrometer. The LTQ was coupled to an Ultimate HPLC pump (LC Packings; a division of Dionex, San Francisco, CA), which had an initial flow rate of $\sim 100 \mu \mathrm{L} / \mathrm{min}$ that was split precolumn to obtain a flow rate of $\sim 300 \mathrm{~nL} / \mathrm{min}$ at the nanospray tip. Samples were analyzed via two-dimensional liquid chromatography over 23 h by 11 consecutive increasing $(0-500 \mathrm{mM})$ pulses of ammonium acetate salt. Each salt pulse was followed by a $2 \mathrm{~h}$ reverse phase gradient from $100 \%$ aqueous solvent $\left(95 \% \mathrm{H}_{2} \mathrm{O} / 5 \% \mathrm{ACN} / 0.1 \%\right.$ formic acid) to $50 \%$ organic solvent $\left(30 \% \mathrm{H}_{2} \mathrm{O} / 70 \% \mathrm{ACN} / 0.1 \%\right.$ formic acid). During the chromatographic separation the LTQ was operated in a data-dependent mode and under the direct control of the Xcalibur software (Thermo Fisher Scientific). The following parameters were applied to the LTQ MS analyses: nanospray voltage of $3.8 \mathrm{kV}$, heated capillary temperature of $200^{\circ} \mathrm{C}$, and a full mass scan range of 400-1700. MS/MS spectra were acquired in data-dependent mode as follows: 5 MS/MS spectra were obtained following every full scan; 2 microscans were averaged for every full MS and MS/MS spectrum; a $3 \mathrm{~m} / \mathrm{z}$ isolation width was employed; $35 \%$ collision energy was used for fragmentation, and dynamic exclusion was set to 1 with a duration of $3 \mathrm{~min}$. 
Resulting MS/MS spectra were searched using the DBDigger algorithm ${ }^{22,23}$ with a database containing all the non-redundant predicted proteins from A. chlorophenolicus (5,286 entries) and 36 common contaminants (i.e. keratins and trypsin). The proteins in the database were designated according to their IMG gene object IDs from the draft genome sequence (http://img.jgi.doe.gov/cgi-bin/pub/main.cgi). Cluster of Orthologous groups (COG) categories were also extracted from IMG and added to each protein entry. The output data files were then filtered and sorted with the DTASelect algorithm ${ }^{24}$ using the following parameters: fully tryptic peptides only, with delCN of at least 0.08 and cross-correlation scores (Xcorrs) of at least $25(+1), 30(+2)$ and $45(+3)$. At least two peptides had to be identified within the same run in order for a protein to be deemed identified. DTASelect output files were extracted for total proteins, peptides, spectra and sequence coverage for each protein. False positive levels were estimated via decoy database method with a reverse database appended on the end of the forward database ${ }^{14}$. Reverse entries were given a unique identifier and total peptides matching forward entries and reverse entries were calculated using the formula from Peng et al. ${ }^{14}$. False positive rates were calculated for 6 representative runs and resulted in an approximate false positive rate of $2.2-5.7 \%$ per run. It should be noted that only proteins with at least 5 total spectral counts were used for quantitation (discussed below) that further reduced the false positive rate for quantified proteins.

Protein abundance was estimated using a semi-quantitative, label free approach by counting the number of MS spectra for each protein in an individual run ${ }^{25,26}$. Spectral counts from each growth condition and LC-MS analysis were extracted into a single worksheet. Proteins with 5 or fewer total spectral counts across all samples were excluded from the statistical analysis due to low reliability of the abundance of these proteins. The dataset was analyzed using the Poisson regression model that is commonly used for count data based on the assumption that the data have a Poisson distribution, such as frequently encountered when counting a number of events ${ }^{27}$. The Poisson regression model assumes the logarithm of its 
expected value can be modeled by a linear combination of the independent variables. In our analysis, we used spectral counts as the outcome and growth condition as the independent variable. To make the spectral counts comparable across different experiments, we normalized the spectral counts for a protein to the total spectral counts in a specific experiment. In Poisson regression, this is handled by adding the logarithm of total spectral count as an independent variable with a fixed coefficient of 1 . The $p$ values generated by the model were further adjusted using the Benjamini and Hochberg correction to account for multiple comparisons $^{28}$. An adjusted $p$ value of 0.01 (i.e. $1 \%$ False Discovery Rate) was used to select proteins that were differentially expressed between selected groups.

Classification of proteins \& visualization. In order to classify the proteins identified via LC-MS analysis based on enzymatic function, we used the enzyme profiles (as of July 2006) provided by PRIAM ${ }^{29}$. For all predicted protein sequences, a RPS-BLAST ${ }^{30}$ against the enzyme profiles was performed and the results were parsed according to the cutoffs given by PRIAM. Identified enzymes were then mapped to KEGG pathway maps ${ }^{31}$ based on whether their abundances were found to be changed in the respective comparison.

\section{Results and Discussion}

Using the shotgun proteomics approach we could identify between 1645 and 2074 proteins per sample and 3773 non-redundant proteins in total from samples from all growth states, including growth at different temperatures and on different phenolic compounds, and a mutant with an inactivated 4-CP degradation pathway during growth on phenol (Supplementary Table 1). The number of proteins, peptides and spectra from each growth condition and biological replicate are shown in Table 1 . The draft genome of $A$. chlorophenolicus at the time of screening contained 5286 potential protein coding genes and since not all of these are expressed at any given time (i.e. typically only a third are expressed in any given growth condition due to gene regulation), this is excellent coverage of the predicted proteome of this 
microorganism. A. chlorophenolicus was found to have large differences in its proteome depending on the growth temperature or growth substrate. Some of the most abundant proteins regardless of growth substrate or temperature were e.g. a monooxygenase (2500143301) (previously reported as CphC-I ${ }^{19}$ ), a chaperonin GroEL (2500146253) and a chaperone protein DnaK (2500143310) as well as a Succinyl-CoA synthetase (2500145054). The most abundant proteins in each growth condition are listed in Table 2.

Proteins from each growth condition were grouped in clusters of orthologous (COG) categories, although please note our disclaimer that these groupings were only made using a draft genome and they are likely to change with a completely finished genome. Still, it enabled us to make comparisons between the growth conditions. At this high level of analysis, however, no major differences were seen between the different growth conditions though minor differences were noted (Supplementary Table 2). The dominant COG categories included hypothetical or conserved hypothetical proteins, amino acid transport and metabolism, translation and energy production. While proteins were found in all categories, some including cytoskeleton, motility, chromatin structure and RNA processing and modification had only 1-4 protein identifications per growth state. This is not surprising since some of these functions are rarely seen or not used at all in bacteria. A "core" proteome was extracted that contained only those proteins found in all growth conditions and biological replicates. In total 738 proteins were found in all samples and biological replicates (Supplementary Table 3), interestingly these had the same distribution of COG categories as the entire set (Supplemental Table 2). Proteins found in this subset included many absolutely necessary for growth including most of the ribosomal and translation proteins, transcription proteins, chaperones, oxidative phosphorylation proteins, and other core metabolic pathways. Interestingly, many hypothetical or conserved hypothetical proteins were found in the core proteome suggesting a critical need for these proteins.

An overall comparison of 1678 genes showing significantly different expression profiles in 
comparisons between at least two growth states is shown in Figure 1. The main findings from these comparisons can be summarized as follows: 1) The major differences in protein expression depend on the substrate and phenol is very different from the other two substrates.

2) Among samples grown on 4-NP and 4-CP, the temperature effect is stronger than the substrate effect. 3) In comparisons of the wild type and mutant strains grown on phenol, the temperature effect is stronger than the mutation effect. 4) Cultures grown on phenol are more sensitive to temperature changes than those grown on 4-NP and 4-CP. The different individual comparisons are discussed in more detail in the following sections. Due to the large number of significant changes in levels of many different proteins it is difficult to dissect the complex interplay between regulation of their expression and functional significance. However, through deep exploration of the proteomes we found indications of interesting and sometimes unexpected mechanisms for stress adaptations in this species and some of these are highlighted in the following sections.

\section{Differences in protein expression at $28^{\circ} \mathrm{C}$ vs. $5^{\circ} \mathrm{C}$}

\section{$\underline{\text { Cold shock proteins }}$}

In a preliminary experiment, 2D-polyacrylamide gel electrophoresis revealed several differences in the proteomes of $A$. chlorophenolicus cells grown at $5^{\circ} \mathrm{C}$ compared to cells grown at $28^{\circ} \mathrm{C}$, irrespective of the growth substrate (data not shown). One spot was prominent in $5^{\circ} \mathrm{C}$-cultures but not present or faint at $28^{\circ} \mathrm{C}$. This spot was de novo sequenced and identified as a putative DNA-binding cold-shock protein, homologous to the CapA protein found in A. globiformis SI55 $5^{32}$.

Subsequently, we investigated the same temperature growth conditions using the shotgun proteomics approach. Hundreds of proteins differentiated between the two growth temperatures. The same putative cold-shock protein (2500145448) that we found using the 2D gel approach was identified as consistently more highly expressed at $5^{\circ} \mathrm{C}$ in the shotgun proteomics data. Five other homologues to this protein were also expressed in all cultures, 
however their expression was not consistently higher at $5^{\circ} \mathrm{C}$ compared to $28^{\circ} \mathrm{C}$, indicating that these proteins do not offer cold protection only, but have other stress-protective roles as well, as previously suggested ${ }^{33}$.

\section{$\underline{\text { Protein variation at } 5 \text { and } 28^{\circ} \mathrm{C} \text { independent of growth substrate }}$}

Only 25 proteins were consistently significantly differently expressed at the two temperatures regardless of growth substrate (Table 3). Several of these were chaperonins and ribosomal proteins that are known to respond to temperature stress. Some unknown proteins also differed in response to temperature, reflecting the need for future research in the area of temperature adaptations. Only 5 of the 25 proteins mentioned consistently changed in the same direction in response to temperature. These were a putative monooxygenase (2500143405), an alanine dehydrogenase (2500145508), a hypothetical protein (2500145780) (re-named unknown), a formaldehyde dehydrogenase (2500143393), and a putative coldshock DNA-binding domain protein (2500145448). Of these, all but the putative monooxygenase and the formaldehyde dehydrogenase increased at $5^{\circ} \mathrm{C}$ compared to $28^{\circ} \mathrm{C}$. We can only speculate about the roles of these proteins in temperature adaptations at this stage. Alanine dehydrogenase has previously been reported as associated with growth at low oxygen levels and accompanying cell dormancy as well as starvation, nitrogen starvation or salt stress ${ }^{34-37}$, and is necessary for sporulation in Bacillus subtilis ${ }^{38}$. However, to our knowledge it has not been associated with cold growth until now.

\section{Protein variation at 5 and $28^{\circ} \mathrm{C}$ depending on substrate}

Different types and amounts of proteins varied at the two temperatures depending on the growth substrate: 4-CP, 109 proteins; 4-NP, 222 proteins; phenol, 527 proteins. Some of these are listed in Table 4 and discussed further below. In particular, cultures grown on 4-NP reacted differently to changes in temperature compared to those grown on the other two phenolic compounds. Among the proteins up-regulated at $5^{\circ} \mathrm{C}$ compared to $28^{\circ} \mathrm{C}$ in $4-\mathrm{CP}$ and/or phenol cultures but not in 4-NP cultures was an AAA ATPase (ATPases Associated 
with diverse cellular Activities) (2500143793) having chaperone-like functions, and a peptidylprolyl isomerase (2500147455) which facilitates protein folding. Such proteins may help to facilitate replication, transcription and translation processes that have reduced efficiency at low temperatures. In addition, a GplX protein (2500145962) was more highly expressed at $5^{\circ} \mathrm{C}$ than $28^{\circ} \mathrm{C}$ in $4-\mathrm{CP}$ and phenol-grown cultures but not in 4-NP-grown cultures. The GplX protein is involved in glycerol metabolism, indicating that glycerol might play a role in bacterial cold adaptation at least during some conditions in A. chlorophenolicus, as in other organisms, e.g. Saccharomyces cerevisiae ${ }^{39}$, and as for other kinds of stresses, e.g. osmotic stress ${ }^{40}$.

One of the proteins that had a lower abundance during cold growth on 4-CP and phenol was the uncharacterized conserved protein YceI (2500145348). This protein has probable importance for isoprenoid quinone metabolism and for controlling oxidative stress and gene regulation $^{41}$. The role of this protein in adaptation to changes in temperature is currently difficult to predict, if it is not part of a general stress response. It is also discussed in the context of growth substrate adaptations below.

\section{$\underline{\text { Temperature adaptation of membrane fatty acid composition }}$}

Previously, we found that the anteiso:iso ratio of the A. chlorophenolicus membrane fatty acids decreased in response to high temperatures and increasing concentrations of phenolic compounds, the extent depending on the nature of the phenolic compound ${ }^{2}$. The observed relative increase in expression of a dihydroxy-acid dehydratase (2500143431) in response to high temperatures in this study would thus be consistent with the results of the previous study. This indicates a role of this protein in production of iso branched fatty acids. The mechanism that Gram positive bacteria use to control their anteiso/iso ratio is not known, but this could be based on the ratio between the precursors valine and leucine for $i s o$, and isoleucine for anteiso. The results of this study therefore provide a first indication of a mechanism for Gram positive bacteria to control their membrane fluidity, through expression of e.g. the protein 
dihydroxy-acid dehydratase and subsequent production of precursors for iso-branched fatty acids.

Differences in protein expression in response to phenolic substrate. To study differences in protein expression due to the phenolic growth substrate, samples from the temperature growth optimum of $28^{\circ} \mathrm{C}$ were compared. In general, the protein expression pattern was more similar for growth on the substituted phenols, compared to phenol. In the comparison between 4-CP and 4-NP 101 proteins were significantly differently expressed, whereas 255 vs. 203 differed between 4-NP and phenol vs. 4-CP and phenol, respectively. In the latter two lists, 111 protein identities were shared that did not differ between 4-CP and 4NP cultures. This clearly illustrates that 4-CP and 4-NP cultures share a more similar protein expression pattern compared to phenol-grown cultures. This could be a result of common degradation routes for 4-CP and 4-NP (Figure 2) compared to phenol, as suggested in a previous study ${ }^{3}$, and/or due to the higher toxicity of 4-NP and 4-CP compared to phenol. All proteins discussed below are listed in Table 5.

Proteins more abundant during growth on substituted phenols compared to phenol

The YceI protein mentioned above was much more abundant in cultures grown on 4-CP and 4-NP compared to those grown on phenol. This protein was also shown to increase in abundance in Delftia acidovorans after addition of a chlorophenoxy herbicide as a growth substrate $^{42}$. It may be a stress response towards halogenated aromatic hydrocarbons as members of this family are known to control oxidative stress ${ }^{41}$. The probable role of YceI in quinone metabolism may also have importance for the preference of para-substituted phenols, having a quinone-like structure, in A. chlorophenolicus ${ }^{1}$.

We found that a monooxygenase previously reported as CphC-I ${ }^{19}$ (2500143301), corresponding to the oxygenase component of a monooxygenase and part of the proposed 4chlorophenol degradation pathway, was more highly expressed in 4-CP and 4-NP-grown cultures than in phenol-grown cultures. This makes sense considering its predicted role in 
metabolism of 4-CP and 4-NP, but not phenol. In addition, this protein had the highest spectral counts in all samples regardless of growth substrate or temperature.

In addition, several ATP synthases (ATPases) (2500146385 and 2500146382; 2500143793, 2500146381 and 2500146380) were expressed at higher levels during growth on substituted phenols. Previous studies of pseudomonads have shown that the ATP concentration decreases in response to exposure to lipophilic hydrocarbons ${ }^{43,44}$. In addition, it is known that phenolic compounds uncouple cellular respiration ${ }^{45,46}$, which could cause inefficient ATP synthesis and result in low ATP concentrations. Therefore, the increase in expression of ATPases in the presence of 4-CP and 4-NP, relative to phenol, may be an effort to compensate for the decreased ATP concentrations. Such indications of compensation for low levels of ATP have not been reported previously to our knowledge.

Some chaperone and chaperonin proteins were more abundant during growth on substituted phenols compared to phenol: a chaperone DnaK (2500143310) and its co-chaperone, DnaJ (2500144536) that are part of the Hsp70 heat-shock system, involved in protein folding and renaturation after stress; GroEL proteins $(2500146253,2500145671,2500146254)$ and a SufBD protein (2500145932), that is an important cofactor for numerous proteins involved in the SUF system operating under e.g. oxidative stress, which can occur when cells are subjected to lipophilic hydrocarbons as in this study.

Proteins that were specifically higher in abundance in 4-NP grown cultures included those with possible roles in nitrogen metabolite repression, i.e. NmrA family protein $(2500143164)^{47}$ and the dihydroxy-acid dehydratase (2500143431) that was discussed above when comparing growth temperatures, strengthening our hypothesis that this enzyme is associated with iso branched fatty acid synthesis, since we previously found the highest levels of iso branched fatty acids when A. chlorophenolicus was grown on 4-NP2 . $\underline{\text { Proteins with higher abundances in phenol grown cultures }}$ 
Five additional putative monooxygenases in two clusters on separate contigs (2500143405, 2500143406, 2500143407; and 2500144277, 2500144278) were 6-30 times more abundant in phenol-grown wild type cultures than 4-NP or 4-CP-grown cultures. In addition, CphA-II (2500143295), the second hydroxyquinol 1,2-dioxygenase in the previously reported 4-CP degradation pathway ${ }^{19}$ (Figure 2), was at levels almost four times higher for phenol grown cultures than for those grown on 4-CP or 4-NP. This suggests that CphA-II is likely involved in degradation pathways of Arthrobacter chlorophenolicus cells grown on all three phenolic substrates.

Two glycerol kinases (2500146342, 2500146341) and a glycerone kinase (2500143798), were much more abundant in phenol cultures than 4-NP or 4-CP cultures, suggesting that glycerol is used as a reserve carbon source when A. chlorophenolicus is growing on phenol. This data suggests that phenol is not a sufficient energy source on its own, explaining the slow and inconsistent growth seen on this substrate compared to the other phenolic compounds ${ }^{3}$.

Another indication of insufficient energy during growth on phenol is the elevated levels of key enzymes in the glyoxylate bypass during growth on this compound; i.e. isocitrate lyase (2500144161) and malate synthase proteins $(2500143966,2500144162)$. The glyoxylate bypass is a shunt in the tricarboxylic acid (TCA) cycle, permitting the use of fatty acids or acetate as carbon sources to provide intermediates in the TCA cycle (Figure 3a). In addition, the T99 mutant with a disrupted 4-chlorophenol degradation operon, also had much higher levels of the glyoxylate bypass proteins than the wild type strain when both were grown on phenol (Figure 3b, Table 7). Since the mutant is known to grow better on phenol than the wild type $\operatorname{strain}^{3}$, these data suggest that the glyoxylate bypass is a beneficial energy yielding reaction during growth on phenol.

\section{Differences in uptake/transport mechanisms for the different phenolics}

Several uptake and transport-associated proteins also differed in expression levels between phenol and the substituted phenols suggesting that different uptake mechansisms are used for 
transport of these two classes of phenolic compounds. We previously found that when 4-CP, 4-NP and phenol were added together as a mixture, 4-NP was degraded first, followed by 4$\mathrm{CP}$ and then phenol $^{3}$. In addition, phenol degradation did not begin until 4-CP was almost depleted indicating some sort of interaction between the compounds. Examples of transporter related proteins that were only detected during growth on phenol, but not substituted phenols were: extracellular solute-binding proteins $(2500144279,2500145620,2500143411)$, an ABC transporter related protein (2500145130) and a putative ABC-type sulfonate transport system protein (2500145128). In contrast, a different extracellular solute-binding protein (2500144130) was more highly expressed during growth on the substituted phenolic compounds. There were also two periplasmic binding proteins and another extracellular solute-binding protein family 1 (2500145912, 2500144463, 2500144131), mainly expressed in 4-NP cultures, suggesting special transport proteins for this compound. Previous kinetic analyses ${ }^{3}$ indicate that 4-NP and 4-CP are in fact degraded simultaneously, but 4-NP has a faster rate of transport into the cell and this could be due to differences in their pKa values, should the phenolate ion be the preferred uptake substrate in both cases. However, study of the proteomes suggest that the situation is more complex, involving different uptake mechanisms depending on the substrate. The different expression of several $\mathrm{ABC}$ transporter proteins between wild type and the T99 mutant strain is interesting, since our previous study indicated transport competition between 4-CP and phenol ${ }^{3}$.

\section{$\underline{\text { Unknown proteins }}$}

Several unknown or hypothetical (re-named unknown) proteins differed between 4-CP vs. phenol, 4-NP vs. 4-CP and 4-NP vs. phenol-grown cultures; 16, 10 and 23, respectively. None of these proteins was significantly differently expressed across all growth substrates. Eight of these were different when comparing 4-CP and 4-NP vs. phenol, but not between 4-CP and 4NP grown cultures, an additional indication of a similar behaviour of A. chlorophenolicus on substituted phenols compared to phenol. Five were more abundant in phenol-grown cultures 
$(2500145574,2500146173,2500147824,2500146860,2500143408)$ and one of these (2500143408) was almost 10 times more abundant in phenol cultures. There was also a protein that was 4 times more abundant in 4-CP cultures than in the other cultures (2500144629). The large differences we observed in expression of these uncharacterized proteins reflects the need for further research in the area of adaptations to aromatic compounds and their degradation pathways.

\section{$\underline{\text { Wild type versus mutant }}$}

When comparing the proteomes of wild type and mutant T99 strains during growth on phenol at $28^{\circ} \mathrm{C}, 453$ proteins differed significantly in their abundances (see Table 6 for a partial list). Many of the proteins found to a higher extent in the wild type strain compared to the mutant were those in the chlorophenol degradation pathway as expected, since this pathway is disrupted in the mutant ${ }^{19}$ (Table 6). The putative monooxygenases in two clusters on separate contigs (2500143405, 2500143406, 2500143407; and 2500144277, 2500144278) that were abundant in phenol-grown wild type cultures (see discussion above) were not detected in the mutant. Downstream of the disrupted $c p h A-I$ gene in the mutant is an ORF, $c p h X$ (not annotated in the draft genome), similar to an $\mathrm{ABC}$ transporter and this protein was also not detected in the mutant. This is also true of an ABC transporter related protein (2500145130), a putative ABC-type sulfonate transport system (2500145128) and two extracellular solutebinding proteins, family 3 and 5 (2500143411, 2500144279). Thus, the mutation in T99 affects other genes apart from the knocked-out gene, and the mutant might even degrade phenol differently than the wild type.

Interestingly, an extracellular solute-binding protein family 1 (2500143192) was more highly expressed in the mutant compared to the wild type strain and an $\mathrm{ABC}$-transporter related protein (2500143447) was only found in the mutant. These findings suggest that transport of phenol into the cell could be occurring differently in the mutant compared to the 
wild type strain. Since the mutant grows better on phenol than the wild type strain a more efficient transport of phenol into the cell could be an alternative explanation for this finding. Although we do not know the pathway used for phenol degradation in the mutant (or wild type) there are several clues obtained from studying the mutant. The hydroxyquinol 1,2dioxygenase, CphA-I, is evidently redundant for phenol degradation, since the mutant strain can grow better on this compound than the wild-type strain without producing this protein. Although levels of the second hydroxyquinol 1,2 dioxygenase, expressed by $\operatorname{cphA-II}$ in the 4chlorophenol degradation gene cluster, were lower in the mutant than in the wild type it was still expressed at relatively high levels. Since the mutant is unable to grow on substituted phenols, the CphA-II enzyme is not sufficient for that process (Table 6). The two CphA enzymes are sufficiently different at the protein level to be distinguished by high resolution MS, therefore, these peptides were not misidentified. Differences in KEGG metabolic pathways indicated by differences in protein expression between wild type and mutant are shown in Table 7. Besides the differences already mentioned in glyoxylate and dicarboxylate metabolism (see also Fig. 3) and benzoate degradation that encompasses some of the proteins involved in 4-CP degradation, are some major differences in purine and pyrimidine metabolism. Also, some proteins involved in biosynthesis of valine, leucine and isoleucine are higher in the mutant than the wild type.

Conclusion. In summary, the results of this study provide a glimpse of the complicated processes behind adaptation to growth in low temperature as well as to growth on different phenolic substrates. Many adaptation mechanisms are employed by A. chlorophenolicus in response to temperature stress and phenolic substrates, and often the same proteins are expressed as a response towards both kinds of stresses. Increasing studies show that stressinduced proteins are often the same for many different kinds of stresses, and hence maybe their names should be re-evaluated, as in the case of e.g. cold-shock or heat-shock proteins. 
These data have also revealed an unexpectedly complicated machinery of phenol degradation pathway(s) in this organism, a question that requires further research to solve.

Acknowledgements. We want to acknowledge Professor Lawrence P. Wackett, University of Minnesota, for valuable discussions about possible phenol degradation pathways in $A$. chlorophenolicus and Dr. Jörn Kalinowski (Institute for Genome Research and Systems Biology, Center for Biotechnology, Bielefeld University, Bielefeld, Germany) for assistance in identification of up regulated proteins in different growth conditions and assigning these to KEGG maps (Figure 3). The ORNL part of this research was sponsored by a Work For Others with the Swedish University of Agricultural Sciences, Uppsala, Sweden. Oak Ridge National Laboratory is managed by UT-Battelle, LLC, for the U.S. Department of Energy under Contract No. DE-AC05-00OR22725. This study was supported by the Department of Microbiology, Swedish University of Agricultural Sciences, Uppsala, Sweden and in part by the U.S. Department of Energy Contract No. DE-AC02-05CH11231 with Lawrence Berkeley National Laboratory. The draft A. chlorophenolicus genome sequence was provided through a Community Sequencing Project grant to JKJ from the DOE Joint Genome Institute, Walnut Creek, CA, USA.

\section{Supporting Information Available}

Supplementary Tables 1-3 are available free at http://pubs.acs.org.

Supplementary Table 1 contains all proteins identified across all growth conditions with spectral counts for each identification.

Supplementary Table 2 illustrates a comparison of the total proteins found from each COG group for each growth condition as well as a "core" proteome.

Supplementary Table 3 contains all proteins found in all growth conditions and biological replicates, the "core" proteome. 


\section{References}

(1) Westerberg, K., Elväng, A. M., Stackebrandt, E. and Jansson, J. K. (2000) Int. J. Syst. Evol. Microbiol. 50, $2083-$ 2092.

(2) Unell, M., Kabelitz, N., Jansson, J. K. and Heipieper, H. J. (2007) FEMS Microbiol. Lett. 266, 138-143.

(3) Unell, M., Nordin, K., Jernberg, C., Stenstrom, J. and Jansson, J. K. (2008) Biodegradation. 19, 495-505.

(4) Backman, A. and Jansson, J. K. (2004) Microb. Ecol. 48, 246-53.

(5) Backman, A., Maraha, N. and Jansson, J. K. (2004) Appl. Environ. Microbiol. 70, 2952-2958.

(6) Mongodin, E. F., Shapir, N., Daugherty, S. C., Deboy, R. T., Emerson, J. B., Shvartzbeyn, A., Radune, D., Vamathevan, J., Riggs, F., Grinberg, V., Khouri, H., Wackett, L. P., Nelson, K. E. and Sadowsky, M. J. (2006) Public Library of Science Genetics. 2, 2094-2106.

(7) Eng, J. K., McCormack, A. L. and Yates, J. R. (1994) J. Am. Soc. Mass Spectrom. 5, 976-989.

(8) Washburn, M. P., Wolters, D. and Yates, J. R. (2001) Nat. Biotechnol. 19, 242-247.

(9) Liu, H. B., Lin, D. Y. and Yates, J. R. (2002) Biotechniques. 32, 898-+.

(10) Peng, J. M. and Gygi, S. P. (2001) J. Mass Spectrom. 36, 1083-1091.

(11) Hu, Q. Z., Noll, R. J., Li, H. Y., Makarov, A., Hardman, M. and Cooks, R. G. (2005) J. Mass Spectrom. 40, 430443.

(12) Schwartz, J. C., Senko, M. W. and Syka, J. E. P. (2002) J. Am. Soc. Mass Spectrom. 13, 659-669.

(13) Brown, S. D., Thompson, M. R., VerBerkmoes, N. C., Chourey, K., Shah, M., Zhou, J. Z., Hettich, R. L. and Thompson, D. K. (2006) Mol. Cell. Prot. 5, 1054-1071.

(14) Peng, J. M., Elias, J. E., Thoreen, C. C., Licklider, L. J. and Gygi, S. P. (2003) J Prot Res. 2, 43-50.

(15) VerBerkmoes, N. C., Shah, M. B., Lankford, P. K., Pelletier, D. A., Strader, M. B., Tabb, D. L., McDonald, W. H., Barton, J. W., Hurst, G. B., Hauser, L., Davison, B. H., Beatty, J. T., Harwood, C. S., Tabita, F. R., Hettich, R. L. and Larimer, F. W. (2006) J Prot Res. 5, 287-298.

(16) Zhu, W. H., Reich, C. I., Olsen, G. J., Giometti, C. S. and Yates, J. R. (2004) J Prot Res. 3, 538-548.

(17) Kolker, E., Picone, A. F., Galperin, M. Y., Romine, M. F., Higdon, R., Makarova, K. S., Kolker, N., Anderson, G. A., Qiu, X. Y., Auberry, K. J., Babnigg, G., Beliaev, A. S., Edlefsen, P., Elias, D. A., Gorby, Y. A., Holzman, T., Klappenbach, J. A., Konstantinidis, K. T., Land, M. L., Lipton, M. S., McCue, L. A., Monroe, M., Pasa-Tolic, L., Pinchuk, G., Purvine, S., Serres, M. H., Tsapin, S., Zakrajsek, B. A., Zhou, J. H., Larimer, F. W., Lawrence, C. E., Riley, M., Collart, F. R., Yates, J. R., Smith, R. D., Giometti, C. S., Nealson, K. H., Fredrickson, J. K. and Tiedje, J. M. (2005) Proceedings of the National Academy of Sciences of the United States of America. 102, 2099-2104.

(18) Perkins, D. N., Pappin, D. J. C., Creasy, D. M. and Cottrell, J. S. (1999) Electrophoresis. 20, 3551-3567.

(19) Nordin, K., Unell, M. and Jansson, J. K. (2005) Appl. Environ. Microbiol. 71, 6538-6544.

(20) Ram, R. J., VerBerkmoes, N. C., Thelen, M. P., Tyson, G. W., Baker, B. J., Blake, R. C., Shah, M., Hettich, R. L. and Banfield, J. F. (2005) Science. 308, 1915-1920.

(21) McDonald, W. H., Ohi, R., Miyamoto, D. T., Mitchison, T. J. and Yates, J. R. (2002) International Journal of Mass Spectrometry. 219, 245-251.

(22) Tabb, D. L., Narasimhan, C., Strader, M. B. and Hettich, R. L. (2005) Anal. Chem. 77, 2464-2474.

(23) Narasimhan, C., Tabb, D. L., VerBerkmoes, N. C., Thompson, M. R., Hettich, R. L. and Uberbacher, E. C. (2005) Anal. Chem. 77, 7581-7593.

(24) Tabb, D. L., McDonald, W. H. and Yates, J. R. (2002) J Prot Res. 1, 21-26.

(25) Liu, H. B., Sadygov, R. G. and Yates, J. R. (2004) Anal. Chem. 76, 4193-4201.

(26) Zhang, B., VerBerkmoes, N. C., Langston, M. A., Uberbacher, E., Hettich, R. L. and Samatova, N. F. (2006) J Prot Res. 5, 2909-2918.

(27) Dobson. (2001)An Introduction to Generalized Linear Models, 2 ed., London.

(28) Benjamini, Y. and Hochberg, Y. (1995) J. R. Statist. Soc. B 57, 289-300.

(29) Claudel-Renard, C., Chevalet, C., Faraut, T. and Kahn, D. (2003) Nucleic Acids Res. 31, 6633-6639.

(30) Marchler-Bauer, A., Anderson, J. B., Chitsaz, F., Derbyshire, M. K., DeWeese-Scott, C., Fong, J. H., Geer, L. Y., Geer, R. C., Gonzales, N. R., Gwadz, M., He, S., Hurwitz, D. I., Jackson, J. D., Ke, Z., Lanczycki, C. J., Liebert, C. A., Liu, C., Lu, F., Lu, S., Marchler, G. H., Mullokandov, M., Song, J. S., Tasneem, A., Thanki, N., Yamashita, R. A., Zhang, D., Zhang, N. and Bryant, S. H. (2009) Nucleic Acids Res. 37, D205-210.

(31) Kanehisa, M., Goto, S., Hattori, M., Aoki-Kinoshita, K. F., Itoh, M., Kawashima, S., Katayama, T., Araki, M. and Hirakawa, M. (2006) Nucleic Acids Res. 34, D354-357.

(32) Berger, F., Normand, P. and Potier, P. (1997) J. Bacteriol. 179, 5670-5676.

(33) Givskov, M., Eberl, L., Moller, S., Poulsen, L. K. and Molin, S. (1994) J. Bacteriol. 176, 7-14.

(34) Betts, J. C., Lukey, P. T., Robb, L. C., McAdam, R. A. and Duncan, K. (2002) Molecular Microbiology. 43, $717-$ 731.

(35) Lahmi, R., Sendersky, E., Perelman, A., Hagemann, M., Forchhammer, K. and Schwarz, R. (2006) J. Bacteriol. 188, 5258-5265.

(36) Duche, O., Tremoulet, F., Glaser, P. and Labadie, J. (2002) Appl. Environ. Microbiol. 68, 1491-1498.

(37) Hutter, B. and Dick, T. (1998) FEMS Microbiol. Lett. 167, 7-11.

(38) Siranosian, K. J., Ireton, K. and Grossman, A. D. (1993) J. Bacteriol. 175, 6789-6796.

(39) Aguilera, J., Randez-Gil, F. and Prieto, J. A. (2007) FEMS Microbiol Rev. 31, 327-341.

(40) Beales, N. (2004) Comprehensive Reviews in Food Science and Food Safety. 3, 1-20.

(41) Handa, N., Terada, T., Doi-Katayama, Y., Hirota, H., Tame, J. R. H., Park, S. Y., Kuramitsu, S., Shirouzu, M. and Yokoyama, S. (2005) Protein Science. 14, 1004-1010.

(42) Benndorf, D., Davidson, I. and Babel, W. (2004) Microbiology - Society for General Microbiology. 150, 10051014. 
(43) Krayl, M., Benndorf, D., Loffhagen, N. and Babel, W. (2003) Proteomics. 3, 1544-1552.

(44) Loffhagen, N., Hartig, C. and Babel, W. (2001) Ecotoxicology and Environmental Safety. 50, 65-71.

(45) Escher, B. I., Snozzi, M. and Schwarzenbach, R. P. (1996) Environ Sci Technol. 30, 3071-3079.

(46) Terada, H. (1990) Environmental Health Perspectives. 87, 213-8.

(47) Stammers, D. K., Ren, J., Leslie, K., Nichols, C. E., Lamb, H. K., Cocklin, S., Dodds, A. and Hawkins, A. R. (2001) Embo Journal. 20, 6619-6626. 


\section{Table of Contents (TOC) Synopsis}

Arthrobacter chlorophenolicus is a psychrotrophic bacterium capable of growth on different phenolic compounds at high concentrations and at different temperature extremes. The $A$. chlorophenolicus proteome revealed hundreds of differentially expressed proteins, providing clues to stress adaptation mechanisms used by this microorganism. Study of the wild type and a mutant strain revealed insight into degradation pathway(s) for phenol and substituted phenolic compounds and metabolic shifts during growth on these compounds. 


\section{Table of}

Table 1. The total number of proteins, peptides and spectra from each growth condition and biological replicate.

\begin{tabular}{lrrr}
$\begin{array}{l}\text { Growth condition } \\
\text { Wild type }\end{array}$ & Proteins & Peptide IDs & Spectra \\
\hline 150 ppm 4-CP, $28^{\circ} \mathrm{C}$ & 1856 & 14355 & 24213 \\
replicate & 1985 & 17476 & 29275 \\
replicate & 1831 & 16056 & 26946 \\
100 ppm 4-NP, $28^{\circ} \mathrm{C}$ & 1991 & 16298 & 30930 \\
replicate & 1711 & 14385 & 32640 \\
400 ppm phenol, $28^{\circ} \mathrm{C}$ & 1916 & 15304 & 28279 \\
replicate & 1841 & 14132 & 28018 \\
replicate & 1837 & 13192 & 24966 \\
150 ppm 4-CP, $5^{\circ} \mathrm{C}$ & 1988 & 17022 & 30280 \\
replicate & 1943 & 15537 & 28419 \\
replicate & 1804 & 14994 & 27988 \\
100 ppm 4-NP, $5^{\circ} \mathrm{C}$ & 2074 & 16236 & 32830 \\
replicate & 2000 & 16149 & 28191 \\
replicate & 1956 & 16564 & 28333 \\
$\begin{array}{l}400 \text { ppm phenol, } 5^{\circ} \mathrm{C} \\
\text { replicate }\end{array}$ & 2052 & 18124 & 32659 \\
replicate & 2050 & 17924 & 32909 \\
Mutant T99 & 2004 & 16136 & 26593 \\
\hline 400 ppm phenol, $28^{\circ} \mathrm{C}$ & 1645 & 11330 & 27911 \\
replicate & 1650 & 13623 & 22713 \\
replicate & 2121 & 17130 & 29957 \\
400 ppm phenol, $5^{\circ} \mathrm{C}$ & 1777 & 13777 & 31246 \\
replicate & 1980 & 14682 & 30014 \\
replicate & 1955 & 15941 & 31116
\end{tabular}


Table 2. The most abundant proteins (spectral counts) in each growth condition, reported as averages of three replicates.

\section{Protein description}

Monooxygenase (cphC-I) ${ }^{a}$

Ycel family protein

Chaperonin GroEL

Chaperonin Cpn60/TCP-1

Chaperone protein DnaK

Succinyl-CoA synthetase, beta subunit

Chaperonin Cpn60/TCP-1

Extracellular solute-binding protein family 5

Elongation factor Tu domain protein

Glyceraldehyde-3-phosphate dehydrogenase, type I

$\begin{array}{ccccccc}\text { COG } & \text { 4-CP 28 } & \text { 4-CP 5 } & \text { 4-NP 28 } & \text { 4-NP 5 } & \begin{array}{c}\text { Phenol } \\ \mathbf{2 8}\end{array} & \begin{array}{c}\text { Phenol } \\ \mathbf{5}\end{array} \\ \text { Q } & 621 & 498 & 604 & 768 & 470 & 667 \\ \text { S } & 422 & 244 & 423 & 409 & 122 & 82 \\ \text { O } & 384 & 624 & 736 & 443 & 456 & 202 \\ \text { O } & 371 & 465 & 506 & 348 & 311 & 163 \\ \text { O } & 318 & 364 & 456 & 309 & 257 & 258 \\ \text { C } & 244 & 352 & 394 & 353 & 317 & 324 \\ \text { O } & 243 & 288 & 312 & 240 & 195 & 138 \\ \text { E } & 243 & 225 & 314 & 326 & 252 & 380 \\ \text { J } & 189 & 216 & 175 & 119 & 117 & 164 \\ \text { G } & 186 & 223 & 228 & 223 & 206 & 218\end{array}$

Maximum standard variation $=82 \%$. Values in normal font are among the 10 most abundant

for a given growth condition; whereas those in italics are still abundant, but not among the top

10 for all growth conditions and are shown for comparison. COG categories found at http://www.ncbi.nlm.nih.gov/COG/grace/fiew.cgi.

${ }^{\text {a }}$ Reported in ${ }^{19}$. 
Table 3. Proteins differing significantly (spectral counts) between temperatures regardless of growth substrate.

\section{Protein description}

Monooxygenase $(c p h C-)^{a}$

chaperonin GroEL

chaperonin Cpn60/TCP-1 (GroEL)

conserved unknown protein

ATP synthase F1, alpha subunit

ribosomal protein L20

carbohydrate kinase FGGY

protein of unknown function DUF1486

chaperonin Cpn10

ribosomal protein $\mathrm{L} 4 / \mathrm{L} 1 \mathrm{e}$

ribosomal protein $\mathrm{L} 10$

2-oxoglutarate dehydrogenase E2 component

Phosphoglycerate kinase

flavin reductase domain protein FMN-binding $(c p h B)^{\mathrm{a}}$

Hydroxyquinol 1,2-dioxygenase (cphA-II) ${ }^{\mathrm{a}}$

ribosomal protein $\mathrm{L} 18$

ribosomal protein $\mathrm{L} 11$

FAD dependent oxidoreductase

putative cold-shock DNA-binding domain protein

putative monooxygenase

alanine dehydrogenase

CBS domain containing protein

unknown protein

Formaldehyde dehydrogenase glutathione-independent transcriptional regulator, PadR-like family

\begin{tabular}{c|c|c|c|c|c|c|} 
& 4-CP & 4-CP & 4-NP & 4-NP & Phenol Phenol \\
\hline COG & $\mathbf{2 8}$ & $\mathbf{5}$ & $\mathbf{2 8}$ & $\mathbf{5}$ & $\mathbf{2 8}$ & $\mathbf{5}$ \\
\hline Q & 621 & 498 & 604 & 768 & 470 & 667 \\
\hline O & 384 & 624 & 736 & 443 & 456 & 202 \\
\hline O & 371 & 465 & 506 & 348 & 311 & 163 \\
R & 183 & 148 & 50 & 133 & 58 & 145 \\
\hline C & 178 & 131 & 218 & 140 & 96 & 169 \\
\hline J & 141 & 223 & 273 & 168 & 239 & 142 \\
\hline C & 135 & 111 & 101 & 197 & 248 & 206 \\
\hline none & 110 & 215 & 219 & 136 & 125 & 200 \\
\hline O & 103 & 173 & 156 & 82 & 116 & 37 \\
\hline J & 82 & 170 & 191 & 98 & 108 & 86 \\
\hline J & 82 & 141 & 206 & 94 & 106 & 78 \\
\hline C & 130 & 100 & 173 & 124 & 87 & 139 \\
\hline G & 87 & 129 & 98 & 127 & 142 & 112 \\
\hline R & 64 & 29 & 40 & 67 & 64 & 24 \\
\hline Q & 51 & 117 & 56 & 134 & 184 & 133 \\
\hline J & 47 & 75 & 95 & 54 & 38 & 64 \\
\hline J & 37 & 62 & 90 & 48 & 64 & 46 \\
\hline C & 22 & 7 & 4 & 20 & 11 & 29 \\
\hline K & 8 & 43 & 23 & 51 & 19 & 56 \\
\hline C & 7 & 0 & 7 & 0 & 62 & 8 \\
\hline E & 5 & 35 & 4 & 27 & 6 & 94 \\
\hline R & 1 & 8 & 14 & 4 & 13 & 0 \\
\hline none & 0 & 17 & 0 & 16 & 0 & 49 \\
\hline E, R & 20 & 5 & 28 & 10 & 15 & 2 \\
\hline K & 3 & 0 & 0 & 4 & 1 & 10 \\
\hline
\end{tabular}

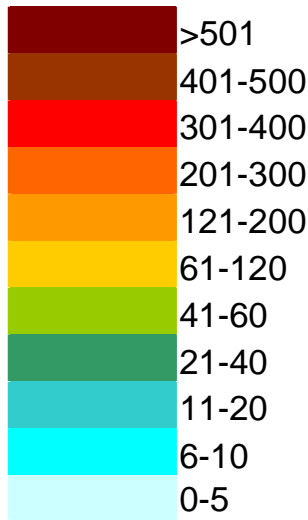

${ }^{\mathrm{a}}$ Genes in previously reported 4-chlorophenol degradation cluster ${ }^{19}$. 
Table 4. Differences in protein expression (spectral counts) in response to growth temperature.

\section{Protein description}

Ycel family protein

ATPase AAA-2 domain protein

Putative cold-shock DNA-binding domain protein

GlpX family protein

Putative cold-shock DNA-binding domain protein

Ribosomal protein L14

Peptidylprolyl isomerase

Dihydroxy-acid dehydratase

Aldo/keto reductase

Conserved hypothetical protein

Protein of unknown function DUF1684

\begin{tabular}{|c|c|c|c|c|c|c|c|}
\hline COG & $\begin{array}{c}\text { 4-CP } \\
28\end{array}$ & 4-CP & $\begin{array}{c}\text { 4-NP } \\
28\end{array}$ & $\begin{array}{c}\text { 4-NP } \\
5\end{array}$ & $\begin{array}{c}\text { Phenol } \\
28\end{array}$ & $\begin{array}{c}\text { Phenol } \\
5\end{array}$ & I.D. \\
\hline$S$ & 422 & 244 & 423 & 409 & 122 & 82 & 2 \\
\hline O & 90 & 199 & 94 & 73 & 58 & 187 & \\
\hline K & 82 & 149 & 145 & 119 & 129 & 190 & \\
\hline G & 66 & 136 & 71 & 68 & 58 & 133 & \\
\hline K & 61 & 138 & 122 & 90 & 102 & 146 & \\
\hline J & 45 & 79 & 83 & 53 & 40 & 52 & 2,3 \\
\hline c & 43 & 68 & 53 & 50 & 48 & 84 &, \\
\hline$E, G$ & 25 & 17 & 43 & 13 & 9 & 9 & 1,3 \\
\hline$F$ & 13 & 39 & 14 & 13 & 9 & 25 & ? \\
\hline$n$ & 6 & 21 & 13 & 15 & 15 & 24 & 3 \\
\hline$n$ & 5 & 0 & 4 & 1 & 37 & 4 & \\
\hline
\end{tabular}

I.D. $=$ Numbers in last column indicate insignificant differences between samples from

cultures grown on the following phenolic compound: 1) 4-CP, 2) 4-NP, 3) phenol. The color legend is the same as in Table 3. 
Table 5. Differences in protein expression (spectral counts) in response to growth substrate.

Protein description

Ycel family protein

ATP synthase F1, alpha subunit

ATP synthase $F 1$, beta subunit

ATPase AAA-2 domain protein

$\mathrm{H}+$ transporting two-sector ATPase alpha/beta subunit domain protein

$\mathrm{H}+$ transporting two-sector ATPase delta/epsilon subunit

Putative cold-shock DNA-binding domain protein

Putative cold-shock DNA-binding domain protein

Putative cold-shock DNA-binding domain protein

Putative cold-shock DNA-binding domain protein

Putative cold-shock DNA-binding domain protein

Putative cold-shock DNA-binding domain protein

NmrA family protein

Dihydroxy-acid dehydratase

Pyruvate kinase

Acetyl-CoA acetyltransferase

Pyruvate carboxylase

Pyridoxine biosynthesis protein

Chaperone DnaJ domain protein

Chaperone protein DnaK

Chaperonin GroEL

Chaperonin GroEL

Chaperonin GroEL

SufBD protein

Asp/Glu racemase

Porphobilinogen deaminase

Porphobilinogen synthase

Glycerol kinase

Glycerol kinase

Glycerone kinase

Isocitrate lyase

Malate synthase A

Malate synthase A

Glyoxylate reductase

Isocitrate dehydrogenase (NADP $(+)$ )

Extracellular solute-binding protein, family 5

Extracellular solute-binding protein, family 5

Extracellular solute-binding protein, family 3

$A B C$ transporter related

Putative ABC-type sulfonate transport system

Extracellular solute-binding protein family 1

Periplasmic binding protein

Periplasmic binding protein

Extracellular solute-binding protein, family 1

Conserved unknown protein

Unknown protein

Protein of unknown function DUF1684

Unknown protein

Unknown protein

Conserved unknown protein
COG 4-CP 4-NP Phenol I.D.

\begin{tabular}{c|ccc|c|c} 
S & 422 & 423 & 122 & 1 \\
C & 178 & 218 & 96 & 1 \\
C & 156 & 137 & 76 & \\
O & 90 & 94 & 58 & 1
\end{tabular}

$\begin{array}{llllll}\mathrm{O} & 90 & 94 & 58 & 1\end{array}$

C

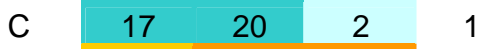

\begin{tabular}{l|l|l|l|l}
$\mathrm{K}$ & 82 & 145 & 129 & 2
\end{tabular}

\begin{tabular}{l|l|l|l|l}
$\mathrm{K}$ & 61 & 122 & 102 & 2
\end{tabular}

\begin{tabular}{l|l|l|l|l}
$\mathrm{K}$ & 8 & 23 & 19 & 2
\end{tabular}

\begin{tabular}{l|lllll}
$\mathrm{K}$ & 42 & 41 & 73 & 1
\end{tabular}

$\begin{array}{lllll}K & 19 & 18 & 3 & 1\end{array}$

\begin{tabular}{l|l|l|l|l}
$\mathrm{K}$ & 7 & 11 & 9 & $1,2,3$
\end{tabular}

$\begin{array}{llll}\text { G,M } & 56 & 134 & 78\end{array}$

\begin{tabular}{l|l|l|l|l}
$E, G$ & 25 & 43 & 9 & 1
\end{tabular}

\begin{tabular}{l|l|l|l|l} 
G & 46 & 93 & 53 & 3
\end{tabular}

\begin{tabular}{l|l|l|l|l} 
I & 72 & 126 & 86 & 2,3
\end{tabular}

\begin{tabular}{l|l|l|l|l} 
C & 58 & 105 & 86 & 2
\end{tabular}

\begin{tabular}{l|l|l|l|l}
$\mathrm{H}$ & 100 & 163 & 116 & 2,3
\end{tabular}

\begin{tabular}{l|lllll}
$\mathrm{O}$ & 16 & 19 & 5 & 1
\end{tabular}

\begin{tabular}{l|ll|l}
\hline & 318 & 456 & 257
\end{tabular}

\begin{tabular}{l|l|l|l}
\hline & 384 & 736 & 456
\end{tabular}

\begin{tabular}{l|l|l|l|l}
\hline & 371 & 506 & 311 & 1
\end{tabular}

\begin{tabular}{l|lllll}
\hline & 243 & 312 & 195 & 1
\end{tabular}

\begin{tabular}{l|lll|l}
$\mathrm{O}$ & 23 & 34 & 13 & 1,3
\end{tabular}

$\begin{array}{llllll}\mathrm{E} & 0 & 0 & 7 & 1\end{array}$

\begin{tabular}{l|l|lll}
$\mathrm{H}$ & 28 & 20 & 14 & 1,2
\end{tabular}

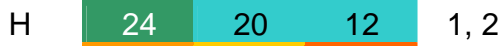

\begin{tabular}{l|l|l|l|l} 
C & 135 & 101 & 248 & 1
\end{tabular}

\begin{tabular}{l|l|l|l|l}
$\mathrm{C}$ & 62 & 50 & 88 & 1
\end{tabular}

\begin{tabular}{l|lllll}
$\mathrm{G}$ & 37 & 55 & 89 & 1
\end{tabular}

\begin{tabular}{l|lllll} 
C & 33 & 31 & 74 & 1
\end{tabular}

\begin{tabular}{l|lllll} 
C & 13 & 20 & 32 & 1
\end{tabular}

\begin{tabular}{l|lll|l}
$\mathrm{C}$ & 13 & 16 & 27 & 1
\end{tabular}

\begin{tabular}{llll|l}
$\mathrm{C}, \mathrm{H}, \mathrm{R}$ & 3 & 1 & 32 & 1
\end{tabular}

\begin{tabular}{l|l|l|l|l} 
C & 60 & 67 & 40 & 1,2
\end{tabular}

E $\quad 0 \quad 0 \quad 20 \quad 1$

$\begin{array}{llllll}\text { E } & 0 & 0 & 4 & 1\end{array}$

$\begin{array}{llllll}\text { E, T } & 0 & 0 & 10 & 1\end{array}$

\begin{tabular}{l|lll|l}
$\mathrm{P}$ & 1 & 0 & 8 & 1
\end{tabular}

$\begin{array}{llllll}\mathrm{P} & 0 & 0 & 11 & 1\end{array}$

\begin{tabular}{l|l|l|l|l}
$\mathrm{P}$ & 21 & 41 & 6 & 1
\end{tabular}

$\begin{array}{llllll}P & 0 & 16 & 0 & 3\end{array}$

$\begin{array}{llllll}P & 1 & 16 & 0 & 3\end{array}$

$\begin{array}{llllll}\mathrm{P} & 16 & 41 & 15 & 3\end{array}$

\begin{tabular}{l|llll}
$\mathrm{R}$ & 183 & 50 & 58 & 2
\end{tabular}

\begin{tabular}{l|lll|l|l} 
none & 31 & 35 & 76 & 1
\end{tabular}

\begin{tabular}{llllll|l}
$\mathrm{S}$ & 5 & 4 & 37 & 1
\end{tabular}

\begin{tabular}{l|lllll} 
none & 32 & 35 & 64 & 1
\end{tabular}

\begin{tabular}{l|l|l|l|l}
$P$ & 16 & 24 & 37 & 1
\end{tabular}

\begin{tabular}{l|ll|l|l} 
none & 19 & 18 & 39 & 1
\end{tabular} 
I.D. Insignificant differences between the following growth states: 1) 4-CP and 4-NP, 2) 4-NP and phenol, 3) 4-CP and phenol.

${ }^{\mathrm{a}}$ Genes in previously reported 4-chlorophenol degradation cluster ${ }^{19}$.

The color legend is the same as in Table 3. 
Table 6. Differences in protein expression (spectral counts) between wild type and mutant strains, both growing on phenol.

\begin{tabular}{|c|c|c|c|}
\hline Protein description & COG & Wt & T99 \\
\hline Monooxygenase $\left(c p h C-l^{\mathrm{a}}\right.$ & Q & 470 & 529 \\
\hline Maleylacetate reductase $(c p h F-I)^{a}$ & C & 196 & 139 \\
\hline Hydroxyquinol 1,2 dioxygenase $(c p h A-I I)^{\mathrm{a}}$ & Q & 184 & 104 \\
\hline Monooxygenase FAD-binding $(c p h C-I)^{\mathrm{a}}$ & $\mathrm{C}, \mathrm{H}$ & 161 & 108 \\
\hline Hydroxyquinol 1,2 dioxygenase $(c p h A-)^{\mathrm{a}}$ & Q & 158 & 3 \\
\hline carbohydrate kinase FGGY & C & 88 & 118 \\
\hline Isocitrate lyase & C & 74 & 540 \\
\hline flavin reductase domain protein FMN-binding $(\mathrm{cphB})^{a}$ & $\mathrm{R}$ & 64 & 5 \\
\hline Putative monooxygenase & C & 62 & 0 \\
\hline Conserved unknown protein & $\mathrm{R}$ & 58 & 303 \\
\hline Putative monooxygenase & C & 57 & 0 \\
\hline Unknown protein & M & 47 & 5 \\
\hline Protocatechuate 3,4-dioxygenase, alpha subunit & Q & 44 & 17 \\
\hline Taurine dioxygenase & Q & 44 & 1 \\
\hline Isocitrate dehydrogenase $(\mathrm{NADP}(+))$ & C & 40 & 63 \\
\hline Protein of unknown function DUF1684 & S & 37 & 0 \\
\hline Aldehyde dehydrogenase & C & 35 & 652 \\
\hline Putative monooxygenase & C & 33 & 0 \\
\hline Glyoxalase/bleomycin resistance protein/dioxygenase & $\mathrm{R}$ & 33 & 12 \\
\hline Malate synthase A & C & 32 & 42 \\
\hline Glyoxalase/bleomycin resistance protein/dioxygenase & S & 29 & 8 \\
\hline Malate synthase A & C & 27 & 149 \\
\hline Putative monooxygenase & none & 27 & 0 \\
\hline Extracellular solute-binding protein family 5 & $\mathrm{E}$ & 20 & 0 \\
\hline Nitrilotriacetate monooxygenase component A & C & 19 & 0 \\
\hline Maleylacetate reductase $\left(c p h F-l^{\mathrm{a}}\right.$ & C & 18 & 19 \\
\hline Putative monooxygenase & none & 15 & 0 \\
\hline Putative ABC-type sulfonate transport system & $P$ & 11 & 0 \\
\hline Phenol hydroxylase domain protein dimerisation & $\mathrm{C}, \mathrm{H}$ & 11 & 5 \\
\hline Glyoxalase/bleomycin resistance protein/dioxygenase & none & 11 & 4 \\
\hline Extracellular solute-binding protein family 3 & $E, T$ & 10 & 0 \\
\hline ABC transporter related & $P$ & 8 & 0 \\
\hline Malate dehydrogenase (oxaloacetate-decarboxylating) $(\operatorname{NADP}(+))$ & C & 7 & 46 \\
\hline Transcriptional activator domain $(c p h S+c p h R)^{\mathrm{a}}$ & K & 3 & 4 \\
\hline Probable molybdate $\mathrm{ABC}$ transporter $(\operatorname{cph} X)^{\mathrm{a}, \mathrm{b}}$ & & 3 & 0 \\
\hline Extracellular solute-binding protein family 1 & G & 2 & 90 \\
\hline Catechol 2,3 dioxygenase & $\mathrm{R}$ & 2 & 1 \\
\hline Conserved unknown protein & none & 0 & 22 \\
\hline$A B C$ transporter related & $\mathrm{V}$ & 0 & 12 \\
\hline
\end{tabular}

${ }^{\mathrm{a}}$ Genes in previously reported 4 -chlorophenol degradation cluster ${ }^{19}$.

I.D. = Insignificant difference; * no significant difference between samples.

${ }^{\mathrm{b}}$ Protein with no corresponding gene annotation in the draft genome.

The color legend and COG definitions are the same as in Table 3. 
Table 7. Altered KEGG pathways in comparisons of wild type (wt) vs. mutant strains.

\begin{tabular}{|c|c|c|}
\hline KEGG pathway & wt Higher & Mutant Higher \\
\hline \multirow[t]{6}{*}{ Citrate cycle } & 6.4.1.1 & 2.3.3.1 \\
\hline & 1.3.99.1 & 4.2.1.3 \\
\hline & 6.2 .1 .4 & 1.1.1.42 \\
\hline & 6.2.1.5 & 1.2.4.2 \\
\hline & & 1.8.1.4 \\
\hline & & 2.3.1.61 \\
\hline \multirow[t]{8}{*}{ Pyruvate metabolism } & 6.4.1.1 & 1.1.2.3 \\
\hline & 2.3.1.9 & 1.2.2.2 \\
\hline & & 1.2.1.3 \\
\hline & & 6.2.1.1 \\
\hline & & 1.8.1.4 \\
\hline & & 1.1.1.40 \\
\hline & & 2.3.3.9 \\
\hline & & 1.1.99.16 \\
\hline \multirow[t]{7}{*}{ Glyoxylate and dicarboxylate metabolism } & 1.2.1.2 & 2.3.3.1 \\
\hline & 3.5.4.9 & 4.2.1.3 \\
\hline & & 4.1.3.1 \\
\hline & & 4.1.1.47 \\
\hline & & 2.3.3.9 \\
\hline & & 5.3.1.22 \\
\hline & & 2.7.1.31 \\
\hline \multirow[t]{3}{*}{ Reductive carboxylate cycle ( $\mathrm{CO}_{2}$ fixation) } & 1.3.99.1 & 6.2.1.1 \\
\hline & 6.2 .1 .5 & 4.2.1.3 \\
\hline & & 1.1.1.42 \\
\hline \multirow[t]{5}{*}{ Purine metabolism } & 3.5.4.4 & 2.7.7.6 \\
\hline & 2.4.2.1 & 1.17.4.1 \\
\hline & 2.4.2.4 & 2.7.7.4 \\
\hline & 3.5 .1 .5 & \\
\hline & 1.7.1.7 & \\
\hline \multirow[t]{4}{*}{ Pyrimidine metabolism } & 2.4.2.1 & 2.7.7.6 \\
\hline & 2.4.2.4 & 1.17.4.1 \\
\hline & & 1.8.1.9 \\
\hline & & 6.3.4.2 \\
\hline \multirow[t]{4}{*}{ Valine, leucine and isoleucine biosynthesis } & & 2.2.1.6 \\
\hline & & 1.1.1.86 \\
\hline & & 4.2.1.9 \\
\hline & & 6.1.1.9 \\
\hline \multirow[t]{3}{*}{ Pantothenate and CoA biosynthesis } & 2.7.8.7 & 2.2.1.6 \\
\hline & & 1.1.1.86 \\
\hline & & 4.2.1.9 \\
\hline \multirow[t]{3}{*}{ 1,4-Dichlorobenzene degradation } & 1.14.13.20 & \\
\hline & 1.3.1.32 & \\
\hline & 1.13.11.37 & \\
\hline \multirow[t]{5}{*}{ Benzoate degradation via CoA ligation } & 1.1.1.35 & \\
\hline & 1.3.99.1 & \\
\hline & 3.5.1.4 & \\
\hline & 2.3.1.9 & \\
\hline & 4.2.1.17 & \\
\hline \multirow[t]{5}{*}{ Benzoate degradation via hydroxylation } & 3.1.1.24 & \\
\hline & 2.8.3.6 & \\
\hline & 1.3.1.32 & \\
\hline & 1.13.11.37 & \\
\hline & 1.13.11.3 & \\
\hline
\end{tabular}


EC-numbers of proteins that are upregulated in the wild type strain compared to the mutant (left column); upregulated in the mutant strain compared to the wild type (right column). 


\section{Figure legends}

Figure 1. Heat map showing differences in protein expression. a) Growth conditions: Upper tier: Green $=$ Phenol, Red $=4-\mathrm{NP}$, Black $=4-\mathrm{CP}$; Middle tier: Black $=5 \mathrm{C}$, Red $=28 \mathrm{C}$; Lower tier: Black $=$ Wild type strain, Red $=$ Mutant strain. b) 1678 genes showing significantly different protein abundances in pairwise comparisons between treatments according to spectral count measurements. Individual genes are represented by a single row, and each replicate culture for each growth condition by a single column. Each cell represents the expression level of a protein under one growth condition, relative to the mean expression level across all conditions. Red represents over-expression, and green represents underexpression. Black cells were not significantly different. c. Tree diagram of cluster analysis showing similarities between samples, using the same color scheme corresponding to the columns given in (a).

Figure 2. 4-chlorophenol degradation pathway, possibly also used for degradation of 4-NP ${ }^{3}$, and the corresponding cph gene cluster in A. chlorophenolicus. An arrowhead indicates the cphA-I gene that was disrupted by transposon mutagenesis in the mutant strain and the corresponding protein in the pathway is crossed out. Adapted from ${ }^{19}$.

Figure 3. Comparisons of glyoxylate and dicarboxylate metabolism for cultures grown on phenol compared to 4-NP or 4-CP (a) and the wild type and mutant strains (b). a) EC-numbers marked green indicate proteins that are up-regulated in phenol-grown cultures compared to cultures grown on 4-NP or 4-CP. b) EC-numbers marked green indicate proteins that are upregulated and red EC-numbers proteins that are down-regulated in the wild type strain compared to the mutant when both are grown on phenol. Grey EC-numbers are those without corresponding proteins in ENZYME database. 
Figure 1

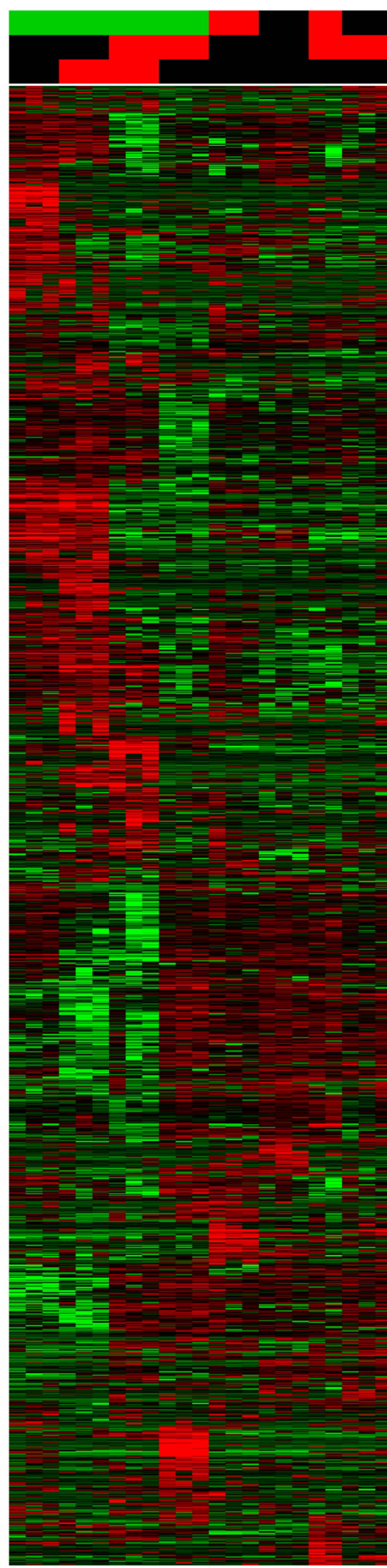

a

b

C

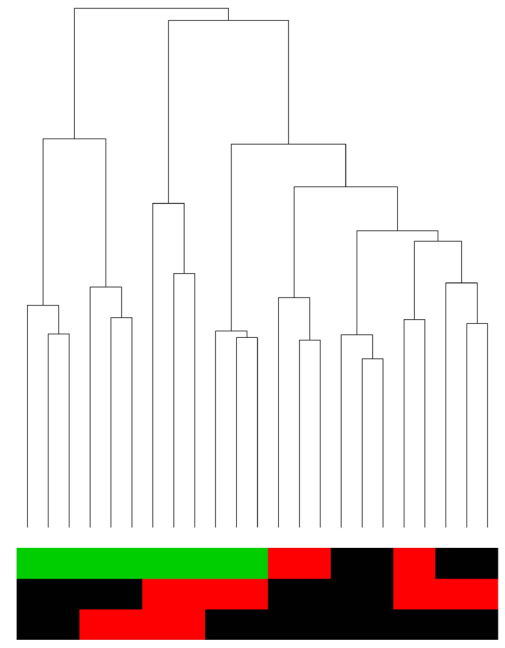


Figure 2

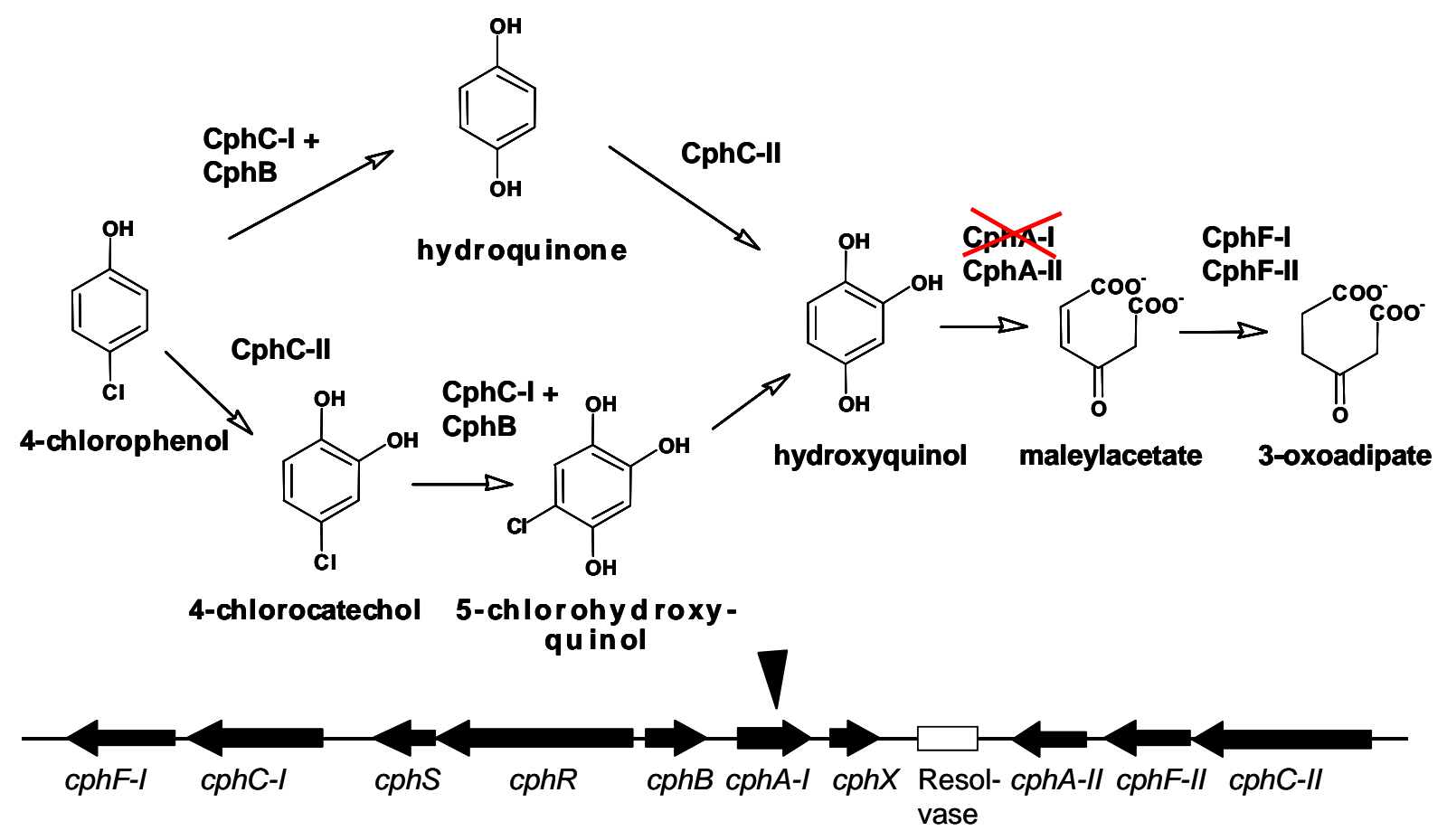




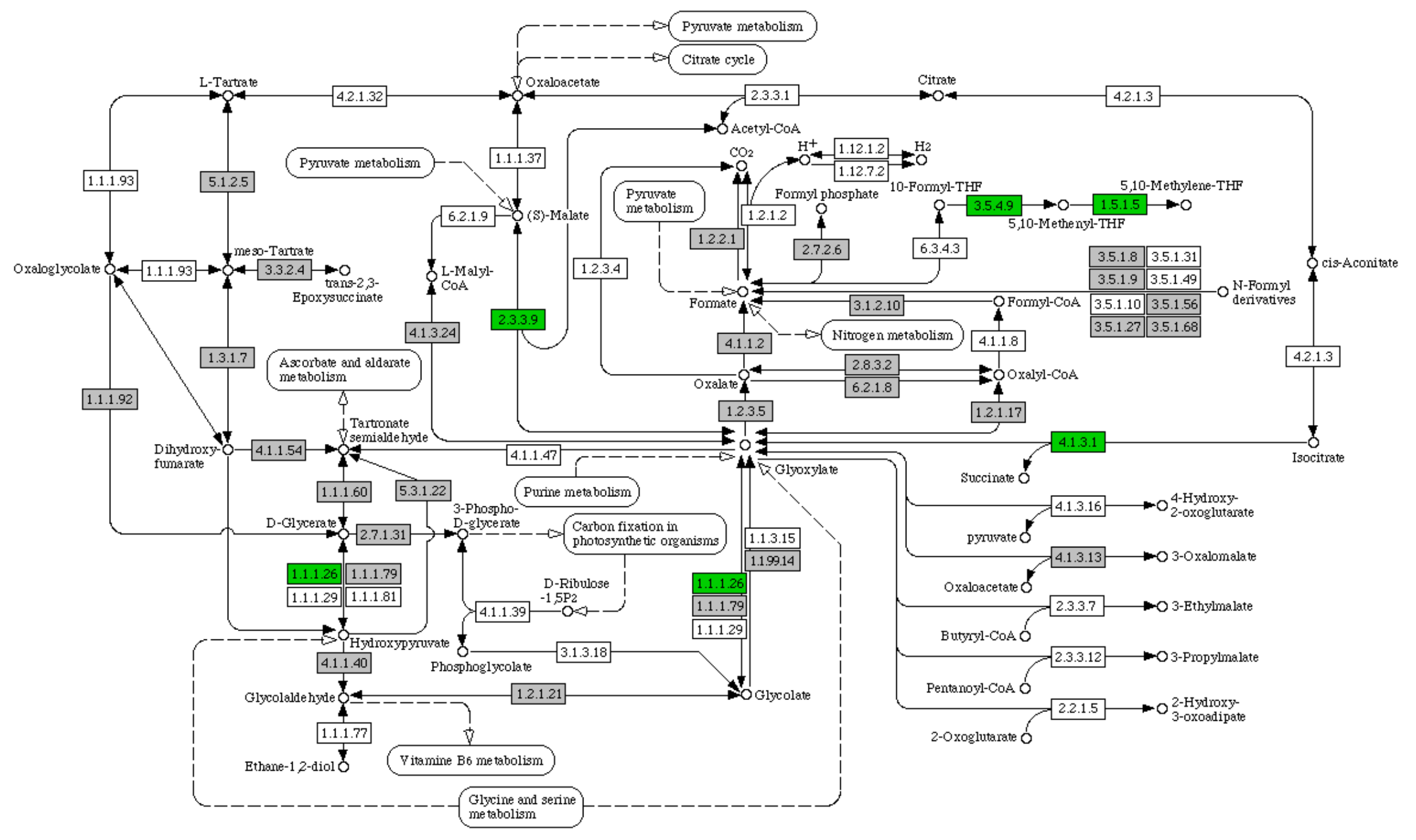




\section{GLYOXYLATE AND DICARBOXYLATE METABOLISM}

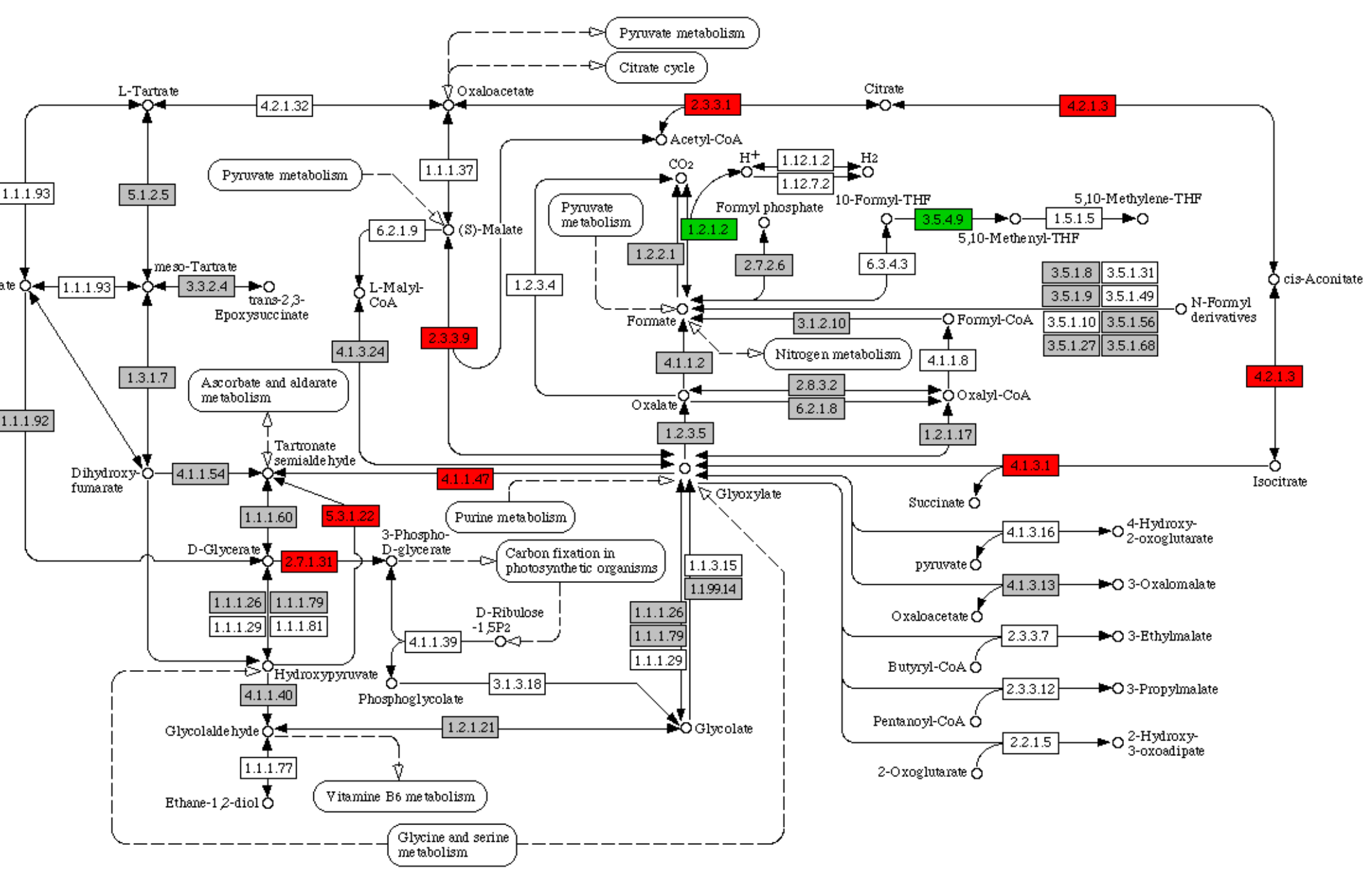

